Article

\title{
"She's Surrounded by Loved Ones, but Feeling Alone": A Relational Approach to Loneliness
}

\author{
Hugo Valenzuela-Garcia ${ }^{1,2, *}$, Miranda J. Lubbers ${ }^{1}$ and Jose Luis Molina ${ }^{1}$ \\ ${ }^{1}$ Department of Social and Cultural Anthropology, Autonomous University of Barcelona, Spain; \\ E-Mails: hugo.valenzuela@uab.cat (H.V.-G.), mirandajessica.lubbers@uab.cat (M.J.L.), joseluis.molina@uab.cat (J.L.M.) \\ ${ }^{2}$ Centre for Entrepreneurship and Social Innovation Research, Autonomous University of Barcelona, Spain \\ * Corresponding author
}

Submitted: 7 June 2021 | Accepted: 7 September 2021 | Published: 15 December 2021

\begin{abstract}
Loneliness poses one of the significant problems of our modern post-industrial societies. Current research on loneliness has been developed primarily by psychology, biomedicine, nursing, and other health-related disciplines, showing a surprising number of variables and risk factors involved in the experience of loneliness, along with positive correlations with premature mortality and morbidity. However, most of these analyses overlook the social interactions and context in which loneliness is experienced. Drawing on a subsample $(\mathrm{N}=24)$ of Spanish "mothers" from impoverished families, the article proposes a mixed-method approach (both relational and interpretative) that may potentially complement quantitative approaches, showing relational and contextual factors that may contribute to a better understanding of the subjective dimension of loneliness.
\end{abstract}

\section{Keywords}

loneliness; mothers; poverty; social support; Spain

Issue

This article is part of the issue "In Good Company? Personal Relationships, Network Embeddedness, and Social Inclusion" edited by Miranda J. Lubbers (Autonomous University of Barcelona, Spain).

(C) 2021 by the authors; licensee Cogitatio (Lisbon, Portugal). This article is licensed under a Creative Commons Attribution 4.0 International License (CC BY).

\section{Introduction}

One of the most striking findings from our research on the socio-emotional impact of poverty in Spain after the 2008 crisis was a deleterious feeling of loneliness experienced by impoverished individuals. Most interviewees had small and unconnected social networks, and suffered various physical and mental health problems. When other poverty-related factors concurred (e.g., unemployment, family ruptures, etc.), the degree of isolation experienced was even higher (Valenzuela-Garcia et al., 2020). A survey administered to over 1000 respondents in 2020 in Madrid (Vidal \& Halty, 2020, p. 125) also showed that, in the lower socioeconomic strata of the population, $77.0 \%$ suffered from loneliness (in contrast with the average in all strata, 34.6\%), 33.2\% experienced lack of company $(2.8 \%$ in the upper stratum and
$5.5 \%$ average), $50.0 \%$ had no friends ( $21.1 \%$ on average), and $75.0 \%$ considered their interpersonal relationships unsatisfactory ( $23.0 \%$ on average). This study also shows that the experience of loneliness was particularly notorious among poor women. Paradoxically, we also found that these Spanish mothers surrounded by dense kinship relationships frequently acknowledged a more intense feeling of loneliness than other individuals with less favourable economic environments and very fragmented social networks (e.g., single adult males, elders, or youths). In other words, the subjective feeling of loneliness did not always correspond with the objective quantity and quality of the individual's social relationships, as already stated by Weiss (1973).

How do social factors and context affect the experience of loneliness in the particular case of these impoverished Spanish mothers? When reviewing mainstream 
contributions on the field, we found that most research on loneliness is quantitative, adopts a psychological or biomedical perspective, is individual-centred, and focuses on risk factors and outcomes' causality (youth, mental illness, etc.). When relational dynamics were considered, contextual factors (e.g., culture, gender, history, economic situation, etc.) were often overlooked. Thus, although factors triggering loneliness are well identified, most studies do not disclose "how/why" contextual and relational factors may interplay, causing the lived experience of loneliness (e.g., how/why loneliness affects more women than men, the poor rather than the wealthy, or the sick rather than the healthy).

This article aims to identify the main causes affecting the subjective experience of loneliness in Spanish mothers embedded in dense kinship networks through a mixed-methods approach based on the interaction between individual factors (e.g., adult women), contextual contingencies (e.g., poverty), and social interactions (i.e., egocentric network analysis). In line with Hersberger's (2003) methodological proposal to combine relational and interpretative appraisals, our approach may complement the extensive quantitative data available, contributing to our understanding of the nuances of loneliness's complex phenomenon.

The following section will present a brief state of the art of conventional research on loneliness, followed by the methodology, results, and conclusions.

\section{Theoretical Background}

\subsection{Loneliness, a Vast Field of Research}

Loneliness can be defined as "the unpleasant experience that occurs when a person's network of social relations is deficient in some important way, either qualitatively or quantitatively" (Perlman \& Peplau, 1981, p. 3). Unlike solitude (i.e., the state of being alone), loneliness involves a subjective and negative experience (Russell et al., 2012; Yang \& Victor, 2011). It is subjective because some individuals may experience loneliness despite high social embeddedness levels, while others may not feel it despite objective low frequency or quality of social contacts (Ozawa-de Silva \& Parsons, 2020). It is negative because the perceived absence of satisfying social relationships involves suffering that may ultimately lead to psychological distress (Cacioppo \& Patrick, 2008; Hawkley \& Cacioppo, 2010; Pinquart \& Sörensen, 2001, p. 245).

Attention to loneliness has recently become a prosperous field of research, producing a plethora of publications in the disciplines of psychology, nursing, and biomedicine (Stein \& Tuval-Mashiach, 2015a; Stek et al., 2005), for loneliness is associated with higher risks of premature mortality (Holt-Lunstad et al., 2015) and morbidity (Waldinger et al., 2015). However, loneliness and health can both influence each other (Ortiz-Ospina \& Roser, 2020), and literature suggests an extraordinary breadth of risk factors and outcomes influenc- ing some collectives more than others (e.g., women, elders and youths, disabled people, unemployed, and single adults) (Victor \& Yang, 2012, p. 94; Vidal \& Halty, 2020). Most research on loneliness also takes a quantitative approach (Stein \& Tuval-Mashiach, 2015a; Vasileiou et al., 2017) and is individual-centred. Data is usually gathered through surveys observing sociodemographic variables (e.g., age, gender, marital status, education, etc.) and the experience of loneliness is documented through closed answers, such as frequency of the feeling of loneliness ("sometimes," "always," etc.), frequency of being social ("once a week," "less than once a month," etc.), the context of socialisation ("at social events," "clubs"), availability of someone to talk to, and the like (Coyle \& Dugan, 2012; De Jong Gierveld, 1998). Usually, answers are later aggregated into a composite index to detect correlations between risk factors and outcomes. Thus, although these quantitative approaches successfully detect "what" causes the feeling of loneliness (factors), they usually do not clarify "how/why" these mechanisms interact in a given context, or "how/why," under similar circumstances, some people experience loneliness while others do not. In a nutshell, most approaches fail "to address the existential aspect of loneliness" (Stein \& Tuval-Mashiach, 2015a, p. 212, emphasis added) and to understand "the fundamental meaning of the lived experience of loneliness" (Pinquart \& Sörensen, 2001, p. 245; see also Karnick, 2005).

\subsection{Relational and Qualitative Approaches to Loneliness}

Beyond the mainstream quantitative and correlational approaches to loneliness, we also found alternative relational and qualitative-oriented appraisals.

Weiss' $(1973,1974,1998)$ seminal theory of social needs sustains that specific social provisions are critical protective factors against loneliness (for a synthesis see Cutrona \& Russell, 1987). According to Weiss (1973), loneliness entails a complex set of feelings resulting from unsatisfied social relationships that may generate social (i.e., lack of integration into a meaningful social network) and/or emotional loneliness (i.e., absence of an attachment or emotional bond with another person). Weiss (1974) established six different social provisions (or functions) which, when lacking, may cause the feeling of loneliness: attachment (i.e., emotional closeness from which one derives a sense of security); social integration (i.e., a sense of belonging to a group that shares similar interests, concerns, and recreational activities); reassurance of worth (i.e., recognition of one's competence, skills, and value by others); reliable alliance (i.e., the assurance that others can be counted upon for tangible assistance); guidance (advice or information); and opportunity for nurture (or the sense that others rely upon one for their well-being). Later, psychologists produced several scales and instruments to measure social dispositions, demonstrating their validity and reliability (Cutrona \& Russell, 1987). 
According to Cutrona and Russell (1987, p. 40), Weiss' social provisions are very much in line with the contemporary use of social support in social network analysis, which considers three types of supportemotional, tangible, and informative (see Schaefer et al., 1981)-embedded in one's network through different kinds of relationships, e.g., intimates, relatives, friends, co-workers, etc. (McCarty et al., 2019; Thoits, 2010). From a relational perspective, it is assumed that high degrees of cohesion, network diversity, and reciprocity are crucial factors in reducing loneliness (De Jong Gierveld, 1998, pp. 74-75). However, overall network size by itself is not a consistent loneliness predictor in cross-sectional analyses (Kovacs et al., 2021, p. 1) since networks primarily composed of kinship ties present a higher risk of loneliness than those that are more heterogeneous (Dykstra, 1990). Cacioppo et al. (2009) also show that network density can have negative effects during periods of change (e.g., divorce). Thus, the extent to which network size, structure, or composition help protect against loneliness during periods of prolonged isolation remains understudied (Ortiz-Ospina \& Roser, 2020). Furthermore, these relational-oriented perspectives do not detail how social dispositions are distributed and interact (and to what extent) within a contextual setting, causing either emotional or social loneliness.

For relational approaches to loneliness to gain full potential, context needs to be considered beyond individual-centred perspectives:

[Loneliness] is not just a matter of individual psychology or cognition, but [it is] inherently social, cultural, and relational... framed as an emergent relational process tied to social practices and places, themselves embedded in political economy, structural violence, and gendered cultural expectations, raced, and classed. (Ozawa-de Silva \& Parsons, 2020, pp. 613-620)

In summary, loneliness has been mainly approached by quantitative and individual-centred perspectives from the health sciences. Although qualitative research on loneliness is gaining momentum, it is still scarce and limited to health and age group studies (Lindgren et al., 2014; Stanley et al., 2010; Yu et al., 2020) that frequently disregard contextual factors fundamental to unravel some of the complexities and nuances of loneliness.

Next, we will describe the methods, followed by the results of our analysis of subjective loneliness in the case of Spanish mothers, and will end with the conclusions.

\section{Methods and Ethics}

The article draws on two cross-sectional research projects about personal networks and poverty in post2008 crisis Spain between 2016 and 2020. The first project was developed in Catalonia $(N=61)$ between 2015 and 2020 and focussed on households and liveli- hood strategies, including participants and non-clients of social and charity services. The second project was developed between 2019 and 2020 in four different geographical spots in Spain ( $N=20$ ), it was explicitly addressed to charity users, and particular attention was paid to the emotional effects of poverty. Criteria for case selection included being resident in Spain, an age of 18 years or older, and being income poor.

Both projects used non-probabilistic purposive sampling (to maximise diversity in gender, age, household composition, nationality, locality, and employment status). The whole sample consisted of 81 people, 47 women and 34 men, with an average of 48.2 years (range 19-80). Most were born in Spain ( $n=66$ ). Twenty-one respondents lived within nuclear families (e.g., couple with children), five in a couple without children, 11 were single parents with children, 30 were single, seven divorced, one widow without children, eight lived in three-generation households, and six lived in other types of households. At the time of the interview, 46 people were working temporarily, and the rest remained in a state of long-term unemployment, were retired, pensioners, or had other employment statuses. Nine had no formal educational training, 23 accomplished basic studies, 36 secondary or technical training, and 13 higher studies.

\subsection{Sampling}

For this article, we specifically focus on women ( $N=24)$ embedded in family households of different kinds (nuclear families, divorced mothers with children, extended families, new family arrangements, etc.), which showed remarkedly similar characteristics in terms of contextual setting (poverty and economic needs), personal characteristics (women, mothers, embedded in family structures, with health problems and depression), and network volume, structure, and composition. For the sake of representation, we chose four typical cases (i.e., case studies) of wives embedded in nuclear families, a case that shows recurrent trends of the whole subsample. Differences and patterns among all the cases will be briefly synthesised in the results section.

\subsection{Mixed-Methods Approach}

Both research projects adopted a mixed-method approach consisting of multi-sited fieldwork (Falzon, 2009), face-to-face qualitative semi-structured interviews (with a length of between and 1.5 and 4 hours), and computer-assisted personal interviews. Anthropological fieldwork is a non-invasive technique of contextual observation that provides a considerable amount of data about the context (socioeconomic, cultural, physical environment, sensory aspects), the processes and actors involved, the nature of the interactions, and all those seemingly tiny details which are often taken-for-granted but nevertheless may explain the different reactions of 
individuals exposed to the same phenomenon. The fieldwork was carried out in the charitable care centres and their various dependencies, in public spaces, workplaces, and, when possible, in the informants' homes. The semistructured interview consisted of three parts: The first collected primary sociodemographic data (age, marital status, number of children, level of studies, etc.) and the second explored the individual's life history focusing on labour, health, household practices, and family situation. The final part explored the emotional aspects involved in the experience of poverty and isolation. All interviews were recorded, transcribed, and analysed, applying codes and contextual data, with the prior consent of informants.

\subsection{Interviews, Data, and Coding}

The semi-structured interview consisted of four main parts, exploring: (a) life history (e.g., socioeconomic background, academic and professional experiences, potential poverty triggers, etc.); (b) change of habits and deterioration of social relationships (leisure, nature of relationships, type of support received, etc.); (c) interaction within the charity context (e.g., access, support, network, etc.); and (d) emotional aspects of poverty (e.g., feelings, perceived social deficiencies, the experience of loneliness, stigma, etc.). We further explored qualitative aspects of the relationships and feelings between ego, primarily family, distant relatives, neighbours, and friends based on the network graphics. Elicitation and introspection were fundamental during the interviews, using the network graphs as a guide to gain qualitative depths (Hersberger, 2003). All the interviews were carried out in friendly and quiet spaces, without time limitations, to allow the interviewee to introspect and thus transmit her experience in her own words. As Stein and Tuval-Mashiach (2015b) show in the case of Israeli veterans, the process of sharing their emotional load with someone ready to pay attention without judgment was a pivotal element to explore these feelings and emotions: "We all need to sense that others experience, feel, think, evaluate, and altogether view the world as we do... this is what motivates people to tell stories of those experiences" (Stein \& Tuval-Mashiach, 2015b, p. 13).

\subsection{Network Analysis}

For personal network analysis, we used the open-source Egonet software, which integrates questionnaires, analysis, and visualisation (McCarty et al., 2019), allowing the empirical study of the current social relationships the individual (ego) maintains with the rest of the network members (alter). Data was gathered according to the type of support received and the characteristics of the alter (age, sex, role, socioeconomic status, etc.). Respondents were presented with free-list "name generators," which are questions to elicit a list of people with whom respondents felt close, who gave them emo- tional, financial, and material support. Next, we asked about the attributes of each nominee: for example, the type of relationship, the emotional closeness, or the perceived relative financial situation (would you say that the financial situation of [nominee's name] is "much better," "a little better," "more or less the same," or "worse" than yours?). For the cases here selected, we draw on the following data: sex; type of relationship with ego ("father," "friend," "professional worker," etc.); perceived degree of proximity ("I feel close," "I feel very close," etc.); interaction frequency ("I meet very often," "often," "rarely," etc.); duration of relationship ("less than 1 year," "between 1 and 5 years," "more than 5 years," etc.); the perceived financial situation of the alter from the ego's point of view ("better than me," "same as me," "worse than me"); and occupational background ("high," "medium," "low professional profile"). Finally, to visualise the network, we gathered information on the relationships between the alters (does Y1 know Y2, Y3, Yn?). For further details see Lubbers et al. (2020).

\subsection{Ethics}

Both research projects comply with the ethical research standards with human subjects. Names and direct identifiers were anonymised, and sensitive information was removed. All participants were informed about the study's objectives and procedures, their voluntary participation, and their right to leave the interview at any time. All individuals who participated in the research were provided with an informed consent document that both parties signed, and the UAB ethics council approved the research proposal.

\section{Results}

\subsection{General Patterns and Trends}

Before engaging in detail with four cases selected from the subsample ( $N=24)$, we will summarise some main trends and patterns: In the subsample, 13 women were wives/mothers embedded in nuclear families; seven were divorced mothers (one widow) with children; two were part of extended families (husband, children, and other members, such as mother or mother-in-law); and two lived in couple without children. The average age was 50.2, with a minimum of 26 and a maximum of 67 years. Twenty-two women had children (an average of 2.5 children per woman, a maximum of six and a minimum of one), and most had suffered a process of downward mobility and impoverishment from the 2008 crisis onwards. In most cases, material support, when provided, came from charities, siblings (brothers and sisters), and cognates (parents and parents-inlaw), with emotional support usually being provided by husbands, older children, and close female friends, where available. 
Compared with men, the manifestation of loneliness was much more frequent among women. In the two cases of extended families (with the presence of elderly family members who economically contributed to the domestic unit) and couples without children, loneliness was not explicitly reported, probably because they were embedded in wider social networks. Besides, despite living in a delicate economic situation, women who did not express loneliness usually felt "supported" by their husbands, children, friends, and other family members. The presence of work, their networks' heterogeneity (in terms of components), emotional stability with husband and children, and the presence of friends seemed to counteract loneliness.

Loneliness was widespread among divorced mothers with children and unemployed wives/mothers integrated into nuclear families. Nineteen out of twenty-four women reported feeling lonely and expressing the need "to talk with other people." For them, emotional support seemed more relevant than material aid and advice. These women had some trends in common: They were unemployed or underemployed (although many had previously had more stable jobs); showed a high prevalence of physical health problems (chronic pain, anaemia, osteoarthritis, anorexia, obesity, along with other severe diseases such as cancer), depression and stress; suffered the extra burden of caring, housework, and responsibilities; lacked spare or personal time, and had little interaction outside the domestic unit (they used to interact sporadically with neighbours and school parents through WhatsApp, and new charity acquaintances rarely ended up in friendship). In most cases, women searched for support and assumed the primary responsibility for domestic and family care, prioritising their children's well-being. Being the depository of emotional load and problems also contributed to feelings of loneliness.

All these facts not only compromised the autonomy, mobility, and sociability of these women but also had a negative emotional impact on them which was exacerbated by feelings of guilt (for not keeping up with the house or not being able to take care of their children when working), tensions with the husband and children, and their pessimistic and hopeless vision of the future.

\subsection{Emotional Loneliness and Spanish Mothers Embedded in Family Households}

This section will present the findings, taking four cases as a proxy of the subsample of mothers embedded in impoverished family households. The four cases assemble a great deal of the subsample's diversity and backgrounds: families that bring together three generations; extended families lead by single/divorced mothers; nuclear families linked to extended relative networks; ordinary nuclear families that suffered downward social mobility; and the figure of a wife/mother in the social networks as the primary breadwinner and emotional support provider. In the results, we will also include ref- erences to Weiss' (1974) social provisions for the sake of coherence with the theoretical background. After using these four examples to disclose the relational and ethnographic context in which loneliness is experienced, we will summarise general traits in network structure, context, factors, and individual characteristics.

\subsubsection{Encarna}

Encarna is a 62-year-old married mother of six. Her family managed a small business that did not resist the 2008 crisis' impact, so she and her husband stopped paying the mortgage and were evicted. As she puts it, "as we are gipsies, when the owners see the last name, they do not want to rent us." After a few months of being unemployed, her husband had a heart attack, and she, with a $30 \%$ disability, was unable to manage the business, so their finances completely fell apart and she started suffering depression:

I want to be alone. There are days when one wouldn't get out of bed, but you do it for your children and grandchildren....My husband stays at home the whole day watching TV, and even his grandchildren bother him. And he argues all the time.

The whole family (parents, children, in-laws, grandchildren) had previously met every weekend and ate together, but circumstances (i.e., health problems, lack of resources, listless mood) now prevented them from participating in social events. However, Encarna still is the family's central emotional pillar. "All problems come to me," she says, since she cares for her ailing husband, often travels to visit her 86-year-old mother, and their divorced son and his two children moved in with them a few months ago. The complex interplay of all these factors explains her deep sense of loneliness:

About these things [her depression, her problems with her husband, her loneliness] I can't talk to anyone except the social worker... my children already know the situation, and I'm not going to burden them yet more. With my husband, I avoid talking because we argue. I'm alone; I can't turn to anyone, neither friends nor family.

Encarna's network (see Figure 1) is relatively large (17 members) and dense (i.e., many know each other); apart from a friend and the social worker, it is mostly made up of close family members: her children and husband. The husband occupies maximum centrality, closeness, and betweenness but, as she says, "I cannot count on him" (i.e., he does not support her emotionally). Manuel, the eldest son, is also a source of moral support, but "he has his problems." Her network is markedly homophilic (that is, all members share a similar socioeconomic status), and she does not report relevant relationships nor leisure activities outside the household. 


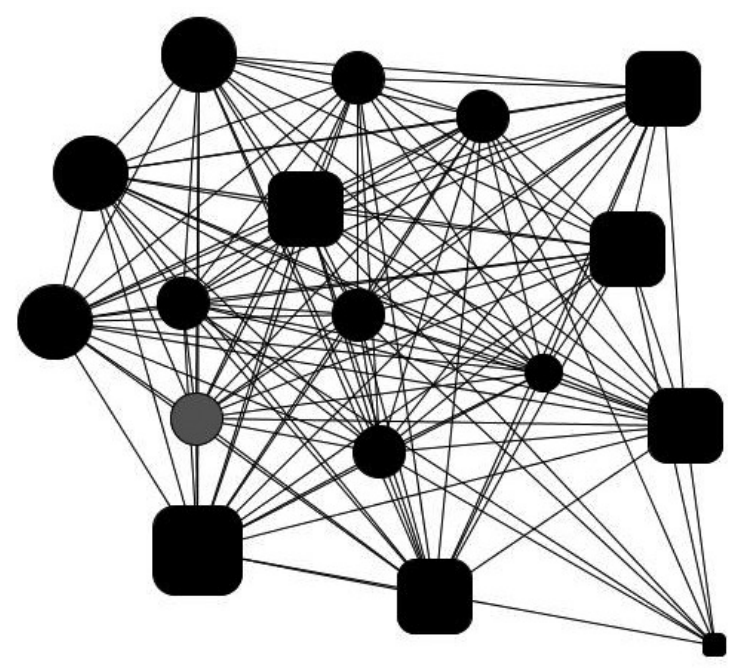

Figure 1. Encarna's personal network. Notes: Node size indicates relational role-size 1 (biggest; closest family: parents, brothers/sisters, and sons/daughters), size 2 (in-laws), size 3 (friends, neighbours), size 4 (distant relatives), size 5 (smallest; social worker, "others"); node shape indicates gender-circle (female), rounded-square (male); node colour indicates proximity: black ("very close"), dark grey (“close"), light grey ("not very close"), white ("not close at all”).

\subsubsection{Amparo}

Amparo, a 54-year-old divorced mother of five with absent fathers, was raised in a humble context. She suffered meningitis, left school early, and began to work in temporary agricultural jobs. Her appearance revealed deprivation (e.g., tangled hair, worn clothes, teeth missing), she was diagnosed with a severe chronic illness a few months ago, and takes antidepressants because "my day-to-day life is difficult." Her youngest son suffers a mental disability, and she visits him once a week at the hospital. She also takes care of her elder mother.

Amparo shares her tiny house with her long-term unemployed adult children and in-laws. She is the primary breadwinner but:

Despite being surrounded, I feel very lonely....Sometimes I'd like to take a never-ending trip and forget many things.

Amparo lives in a tiny rural town, so she has many acquaintances "but few friends," besides a couple of female childhood friends with whom she communicates on WhatsApp, but rarely meets. Although her household environment is tense, she does not leave home much because "I have neither the money nor the habit."

Her dense network is made up of strong ties, yet she "does not feel very close" to some of them, a fact that suggests personal conflicts. She only talks about her problems with her aged mother, her older daughter (who lives away), the social worker (on the right-bottom corner), and with one "not very close" distant female relative (upper-left corner; see Figure 2).

\subsubsection{Laura}

Laura (see Figure 3 ) is a 26-year-old married mother of two daughters. Her husband is unemployed, and she was engaged in a labour reconversion program. She has twelve siblings from different mothers, although "our relationship is very good," she says. She has a central caregiver role-taking care of her younger siblings and stepbrothers, her mother-in-law (suffering from some psychological ailment), and her twenty-four nephews: "They bring them home to me, I'm like the mum of all. And this has made me mature a lot because from the age of seven I already had responsibilities." Laura also decided to seek help because her husband ("who's somewhat depressed at home") was ashamed to do so. When asking if she practised any hobby, she replied:

Before I practised sport. I went to the gym and had friends. Now I have no time or money but other concerns and worries...[Laughing] Furthermore my husband doesn't like much that I go out with new friends [co-workers], especially if they are boys: He is a little jealous!

Laura's network is comparatively extensive (25 members) and dense: However, $70 \%$ are family members (with whom she feels "close" and "very close"), and the rest are friends and neighbours notably embedded in her network (i.e., "many know each other") and "new friends" (recently met co-workers). Although her husband (lower side) is relevant in her network, maximum centrality, betweenness and closeness are occupied by her sister (Cristina) and her in-law (María). Homophily is also high: $72 \%$ of her contacts show a low socioeconomic status and educational background. 


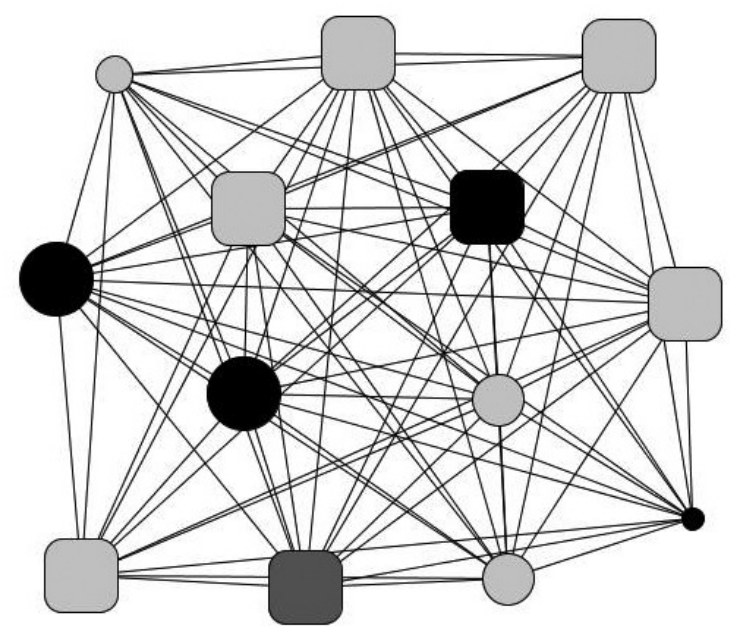

Figure 2. Amparo's personal network. Notes: Node size indicates relational role-size 1 (biggest; closest family: parents, brothers/sisters, and sons/daughters), size 2 (in-laws), size 3 (friends, neighbours), size 4 (distant relatives), size 5 (smallest; social worker, "others"); node shape indicates gender-circle (female), rounded-square (male); node colour indicates proximity: black ("very close"), dark grey (“close"), light grey ("not very close”), white ("not close at all”).

\subsubsection{Isabel}

Isabel (see Figure 4), a 55-year-old married mother of four sons $(30,26,22$, and 20 years old), managed a greengrocery that collapsed after the 2008 crisis. As in Encarna's case, Isabel recurred to social services and found a professional who "listens to you, supports you, and makes you see your problem is not that big" (i.e., emotional support). Her husband lost his job too and, depressed, began to drink more than usual until he found a job as a night taxi driver, which did not help improve the couple's communication. Isabel suffers from chronic pain in her arms and legs, which she attributes to all her suffering. Although the couple maintains a good relationship with their respective families, they did not dare ask them for help: "I don't like to explain my sorrows... everyone has problems." And she adds: "And in the case of friends.... I am not confident enough to explain my life."

Isabel's network is also quite extensive ( 18 members). Her husband occupies maximum centrality, but other contacts (her older son, female friends, relatives, and the social worker) show high degrees of betweenness and centrality. She feels "very close" to $55 \%$ of her contacts and "close" to $38 \%$. In comparison to the other networks, Isabel's is less dense and homogeneous ( $27 \%$ are friends) and shows a lower degree of homophily

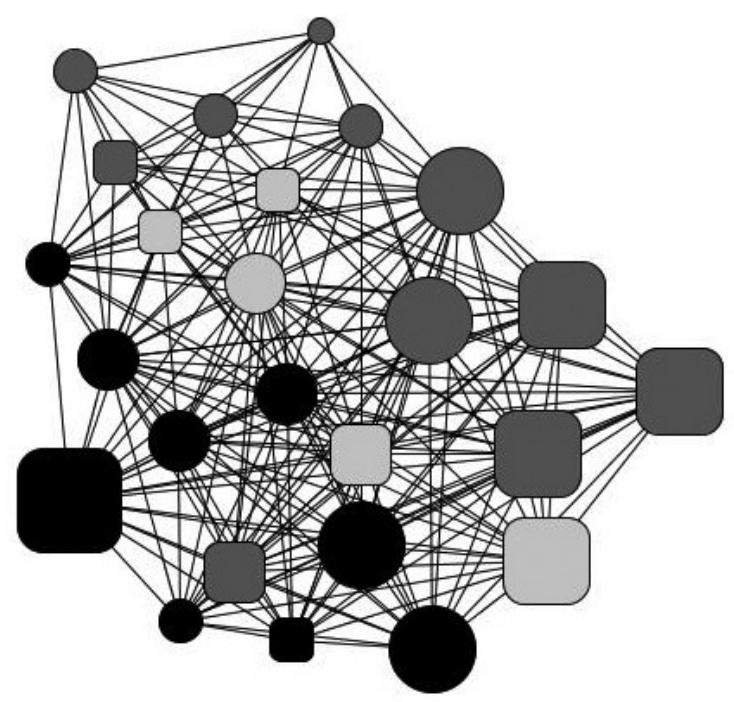

Figure 3. Laura's personal network. Notes: Node size indicates relational role-size 1 (biggest; closest family: parents, brothers/sisters, and sons/daughters), size 2 (in-laws), size 3 (friends, neighbours), size 4 (distant relatives), size 5 (smallest; social worker, "others"); node shape indicates gender-circle (female), rounded-square (male); node colour indicates proximity: black ("very close"), dark grey ("close"), light grey ("not very close"), white ("not close at all"). 


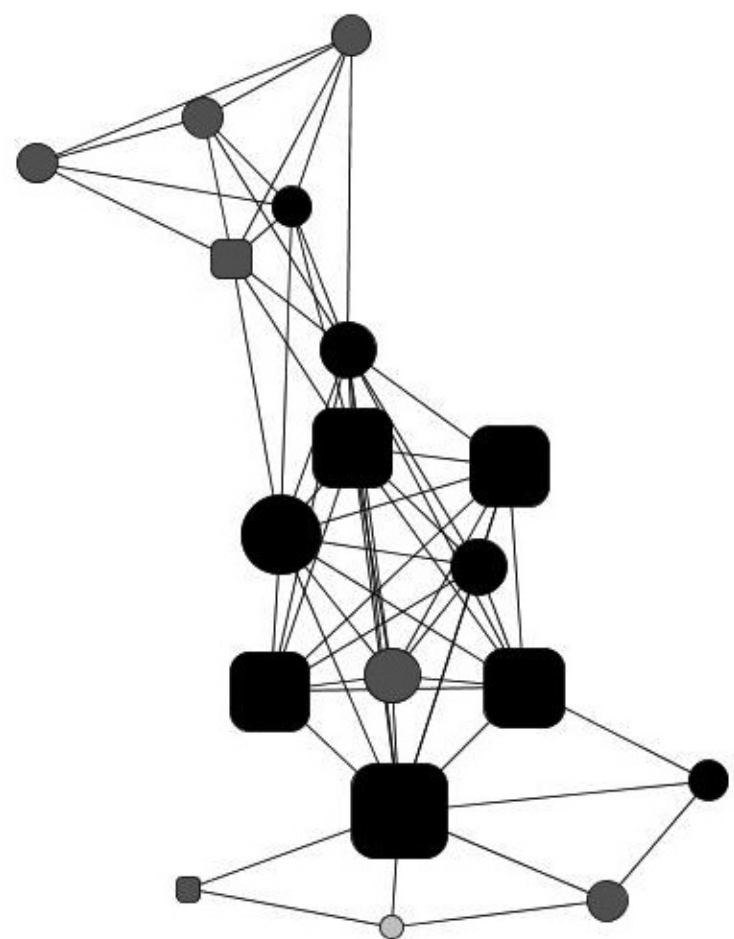

Figure 4. Isabel's personal network. Notes: Node size indicates relational role-size 1 (biggest; closest family: parents, brothers/sisters, and sons/daughters), size 2 (in-laws), size 3 (friends, neighbours), size 4 (distant relatives), size 5 (smallest; social worker, "others"); node shape indicates gender-circle (female), rounded-square (male); node colour indicates proximity: black ("very close"), dark grey ("close"), light grey ("not very close"), white ("not close at all”).

( $50 \%$ have a high educational background and she perceives that $77 \%$ are in a better socioeconomic situation than herself), showing a typical case of downward social mobility that still provides some class resources and social capital (i.e., embedded resources in social networks; see Molina et al., 2019). Although she feels lonely, she gets emotional support from her sister, her oldest son, and a friend. Despite all these difficulties, her priority was to ensure their children's education attainment or, in other words, to secure their cultural capitalunderstood as being non-economic social assets (education, skills, knowledge) that provide a higher status within society and allow social mobility in broader terms (Bourdieu, 1984).

\subsection{Networks}

In most cases, personal networks are very dense ("almost everyone knows each other") and relatively large (mean: 18.25) compared with other poor populations (Bichir \& Marques, 2012) and considering that average individuals' closest "intimate psycho-social nets" include from 20 to 30 people (Pattison et al., 1975). Most networks show just one component (or relational sphere), meaning that the individual lacks other relevant social spheres (e.g., labour). These women are, therefore, encapsulated within a single homogeneous social world made of relatives with a high degree of proximity (e.g., Encarna feels "very close" with $94 \%$ of her network members) and homophily (i.e., ego and alter share similar attributes; see McPherson et al., 2001).

\subsection{Homophily}

Homophily cannot be considered a trigger of loneliness by itself. Nevertheless, when all relationships involve individuals with low economic (i.e., material resources and income) and cultural capital (i.e., education), access to new opportunities, resources, and chances are radically restricted. Here cumulative disadvantage plays against these women: Their low economic and cultural capital makes it difficult for them to expand their dispositions and interests, preventing engagement with other social groups beyond the family domain, i.e., Weiss' (1974) "social integration."

\subsection{Weak Ties}

All networks show just a few weak ties, which are very relevant in linking different groups and provide, therefore, information, mobility, and opportunities (Granovetter, 1973). The low frequency of socialisation beyond the household, which signals social isolation, is the result of their lack of resources and time, as well as the fact that they prioritise caregiving over socializing. Although we found a few confidants outside the domestic milieu, they are often embedded within the same kinship network (e.g., female family members). Alternative means 


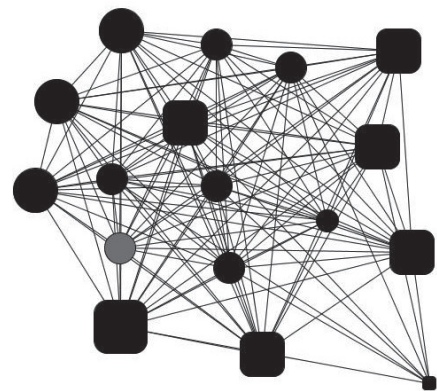

Encarna's network

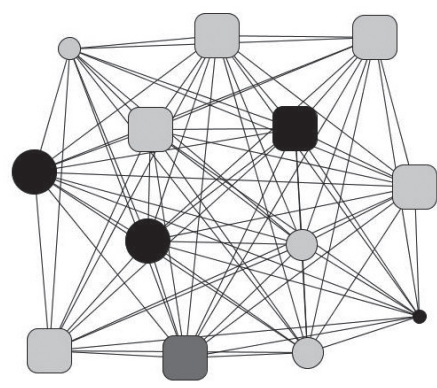

Amparo's network

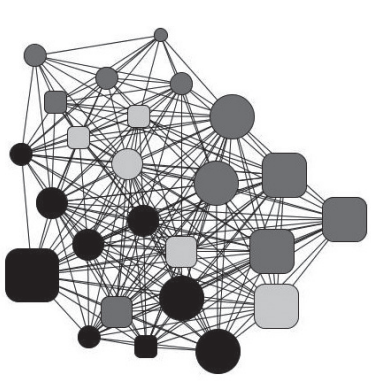

Laura's network

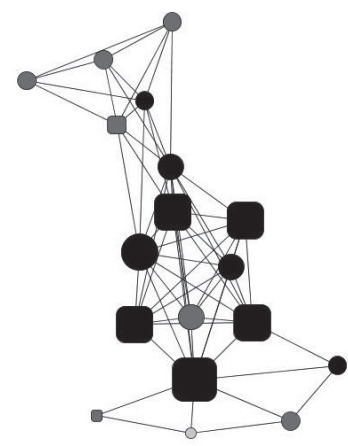

Isabel's network

Figure 5. Comparison of the four personal networks. Notes: Node size indicates relational role-size 1 (biggest; closest family: parents, brothers/sisters, and sons/daughters), size 2 (in-laws), size 3 (friends, neighbours), size 4 (distant relatives), size 5 (smallest; social worker, "others"); node shape indicates gender-circle (female), rounded-square (male); node colour indicates proximity: black ("very close"), dark grey ("close"), light grey ("not very close"), white ("not close at all"); edge shape: line ("know each other"), square with rounded angles ("maybe know each other"), no edge ("don't know each other").

of communication (WhatsApp, Facebook, email, telephone) is not as effective as face-to-face as it does not allow an adequate level of intimacy or confession. While sometimes people confide highly personal matters to people they are not close to, and at times barely even know (Small, 2017), there is no one to talk to. In other words, in Weiss' (1974) terms, "attachment," "social integration," and "reliable alliance" seem to be compromised.

\subsection{Toxic Ties and Weak Emotional Support}

It is generally assumed that someone surrounded by relatives enjoys high emotional support. But in our cases, the situation may be oppressive, as relatives become toxic links (Del Real, 2019) that subtract resources and generate conflict and stress. The partner frequently was a barrier to socialisation due to jealousy, apathy, their need for attention, etc., and women felt emotional support "was not there" when most needed. Furthermore, asking close relatives for help was usually avoided because they did not want to burden them (e.g., "everyone has their problems"), and social workers provided primary emotional support, but necessarily professional, temporal, and limited. Thus, the availability of "reliable alliance" or "guidance," in the sense of Weiss (1974), was deficient in most cases.

\subsection{Dependency}

In all cases, autonomy, self-care, and leisure were severely neglected due to domestic duties and caring tasks, which notably increased the pressure and degree of emotional fatigue and drastically reduced social networks (Juratovac \& Zauszniewski, 2014). This fact is very relevant because it implies a paradoxical finding concerning Weiss' social provisions: In these cases, there is no lack of "opportunity for nurture" (the sense that others rely upon one for their well-being), but on the contrary, an excess that ultimately undermined their self-esteem, limited their autonomy, and prevented other social provisions such as "social integration," "reassurance of worth," "reliable alliance" and "attachment."

\subsection{Gender}

In connection with the previous point, a remarkable gendered dimension of loneliness operates in our cases (see Hochschild, 1997; Jiménez Ruiz \& Moya, 2018). In general, women are exposed to pressuring gendered roles in terms of mothering obligations and duties (e.g., to be a "good mother," marriage vows that encompass a promise to support each other "in sickness and in health," etc.), which may be even more critical in marginal contexts (Gillies, 2007). As we have observed, by prioritising the well-being of others or inverting traditional gender roles (e.g., adopting the breadwinners' role to make ends meet), more stress and pressure is added to the subjective experience of loneliness.

\subsection{Inwardness}

Loneliness is often related to dissatisfaction with existing social interaction, expressed through the sense of misunderstanding (e.g., "they don't really understand"; see Vasileiou et al., 2017) that leads to feelings of void, hopelessness, isolation, and despair (in this case, we observe a lack of what Weiss would call "reassurance of worth" which may be intensified with the suffering of stigma; see Weiss, 1974).

\subsection{Multiple Stigmas}

These women carry on their shoulders the stigma of being poor and lonely and the weight of so-called courtesy stigma (i.e., stigma by association, which burdens 
closely affiliated people; Goffman, 1963). This has also been reported in the case of caregivers of mentally ill family members (Ali et al., 2012; Vasileiou et al., 2017), mothers of children with ADHD (Norvilitis et al., 2002), or families supporting adult members with substance misuse (McCann \& Lubman, 2017). Stigma may lead to a dual isolation in which the stigmatised avoid contact with others, who in turn, avoid contact with them too.

\subsection{Lack of Resources}

In our case, poverty is a significant predictor of loneliness (Refaeli \& Achdut, 2020). For these women, in our increasingly commodified world (Marquand, 2004), the lack of economic resources not only precludes the possibility to outsource housework and caring, but it also limits their access to mainstream leisure, often involving costs in the form of fees, purchases, and tickets, e.g., cinemas, theatres, bars, restaurants, gyms, or various associations. As most of the household members are unemployed, isolation and consciousness of social exclusion tend to be more significant.

\subsection{Health}

Most of these women suffered depression and other types of psychological distress along with a wide array of physical ailments that preclude social interaction and mobility, adding to the feeling of social and emotional loneliness.

\subsection{Personal Variables}

Of course, individual characteristics also play a role in the experience of loneliness. Being women, aged, sick, uneducated, etc., influence the experience of loneliness. However, these personal variables are often attenuated by other interplaying socio-cultural and relational factors rarely considered in the experience of loneliness, e.g., physical appearance (e.g., Amparo), ethnic origin (e.g., Encarna's gipsy origin), or stigma due to downward social mobility (Isabel).

\subsection{Emotional Loneliness}

Most of these women acknowledge emotional loneliness (Weiss, 1973), meaning that a high density of relationships does not necessarily reduce the feeling of loneliness (Cacioppo, et al., 2009). Despite being surrounded by cognates and close relatives, although they affirm that they feel lonely, it does not mean loneliness is an individual-centred feeling, for the phenomenon cannot be fully understood without referring to their social interactions and context. In all these cases, we could argue, emotional loneliness is probably caused by a lack of "attachment" along with a lack of "social integration," "reassurance of worth," "reliable alliance," "guidance," and, in particular, excessive "opportunity for nurturing."
Nevertheless, the way and extent to which such social dispositions interact, causing the feeling of loneliness, for the case of impoverished Spanish women, is hardly understood without minimal references to the context, as we have tried to show.

\section{Conclusions}

Loneliness is a complex, multifactorial, and multicausal feeling. Perhaps, for this reason, there is no consensus on the concept (Stein \& Tuval-Mashiach, 2015a), and while some researchers distinguish between loneliness, solitude, social withdrawal, and social isolation, others entirely disregard the distinction and use these terms interchangeably (Karnick, 2005, p. 11). Quantitative research has shown a vast amount of risk factors and outcomes related to its experience. However, most research fails to unveil the complexities of the subjective experience of loneliness despite the causal associations.

Our main argument is that loneliness is, by definition, a relational category that needs a specific mixed-methods (relational and interpretative) approach to be understood in all its full complexity. This article analyses the experience of loneliness by Spanish mothers of impoverished families through a relationalcontextual perspective that reveals interconnections that are not always straightforwardly evident through conventional research. Thus, to the usual individual variables (e.g., woman, mother, adult, poor, ill, etc.), we added less tangible (but maybe more complex) variables (ethnicity, appearance, stigma, experience of class mobility, etc.) within the framework of their social networks and interactions (e.g., homophily, lack of weak ties, toxic ties, relationships of dependency, etc.), alongside interiorised socio-cultural principles (stigma, unemployment, gender constructions, mothering duties, etc.) in a specific socioeconomic context (i.e., poverty). This provides a more accurate and complex comprehension of the lived experience of loneliness for this specific collective. Thus, in order to fully disclose the lived experience of loneliness, both relational factors and context matter, requiring specific non-quantitative and holistic methods and techniques (participant observation, fieldwork, introspective interviews, elicitation, etc.) to support quantitative data.

While in traditional societies, social exclusion and ostracism are rare and usually regarded as a severe punishment for socially deviant behaviours and attitudes (Söderberg \& Fry, 2017), in our (post)modern industrial societies, loneliness has become a significant problem "worthy of attention in its own right" (Heinrich \& Gullone, 2006, p. 712). Understanding this expanding phenomenon in our modern societies poses an urgent and fundamental challenge due to the large number of harmful effects associated with it. It is striking the mounting frequency of lonely deaths in advanced countries such as Norway (Hauge \& Kirkevold, 2012), the US (Twenge et al., 2019), or Japan (Allison, 2013). What 
is more, loneliness is here to stay, as many contemporary processes suggest: the COVID-19 pandemic's confinement and social distancing (Matias et al., 2020); the spread of remote working (Valenzuela-Garcia, 2020); the collective addiction to personal technologies (Savolainen et al., 2020); population ageing (Golden et al., 2009); increasing rates of divorce and the transformation of traditional family models (Silverstein \& Giarrusso, 2010); the dissolution of community bonds (Putman, 2001); and the ever-expanding anomy and individualisation of our modern societies (Zhao \& Cao, 2010). Furthermore, poverty, in particular, is a strong predictor of loneliness (Refaeli \& Achdut, 2020), for social networks of poor individuals tend to be smaller than those of the non-poor (Bichir \& Marques, 2012).

In summary, we have provided an alternative, mixedmethods approach, to loneliness with may in itself present obvious limitations but could complement other quantitative approaches, attending to both relational and contextual data. A more profound comprehension of these factors in the feeling of loneliness could better inform policies and actions aimed at combating it, envisaging a future society where there is no place for (unwanted) loneliness.

\section{Acknowledgments}

The authors are grateful for the generosity of the participants in this study, as well as the support of FOESSA, the Red Cross, and Caritas. This work was supported by the Spanish Government, Programa Estatal de I+D+i Orientada a los Retos de la Sociedad, del Plan Estatal de Investigación Científica y Técnica y de Innovación 2017-2020 (PID2019-111251RB-I00 (2019-2023)) and by Recercaixa (2015ACUP 00145 (2016-2020)).

\section{Conflict of Interests}

The authors declare no conflict of interest.

\section{References}

Ali, A., Hassiotis, A., Strydom, A., \& King, M. (2012). Self-stigma in people with intellectual disabilities and courtesy stigma in family carers: A systematic review. Research in Developmental Disabilities, 33, 2122-2140. https://doi.org/10.1016/j.ridd.2012.06. 013

Allison, A. (2013). Precarious Japan. Duke University Press.

Bichir, R. M., \& Marques, E. (2012). Poverty and sociability in Brazilian metropolises: Comparing poor people's personal networks in São Paulo and Salvador. Connections, 32(1), 20-32.

Bourdieu, P. (1984). Distinction. Routledge.

Cacioppo, J. T., Fowler, J. H., \& Christakis, N. A. (2009). Alone in the crowd: The structure and spread of loneliness in a large social network. Journal of Personality and Social Psychology, 97(6), 977-991.

Cacioppo, J. T., \& Patrick, W. (2008). Loneliness: Human nature and the need for social connection. Norton $\&$ Co.

Coyle, C. E., \& Dugan, E. (2012). Social isolation, loneliness and health among older adults. Journal of Aging and Health, 24(8), 1346-1363.

Cutrona, C.E., \& Russell, D. W. (1987). The provisions of social relationships and adaptation to stress. Advances in Personal Relationships, 1, 37-67.

De Jong Gierveld, J. (1998). A review of loneliness: Concept and definitions, determinants and consequences. Reviews in Clinical Gerontology, 8(1), 73-80. https://doi.org/10.1017/S0959259898008090

Del Real, D. (2019). Toxic ties: The reproduction of legal violence within mixed-status intimate partners, relatives, and friends. International Migration Review, 53(2), 548-570.

Dykstra, P. A. (1990). Next of non-kin. The importance of primary relationships for older adults' well-being. Swets \& Zeitlinger.

Falzon, M. A. (Ed.). (2009). Multi-sited ethnography. Theory, praxis and locality in contemporary research. Routledge.

Gillies, V. (2007). Marginalised mothers: Exploring working class experiences of parenting. Routledge.

Goffman, E. (1963). Stigma: Notes on the management of spoiled identity. Touchstone.

Golden, J., Conroy, R. M., Bruce, I., Denihan, A., Greene, E., Kirby, M., \& Lawlor, B. A. (2009). Loneliness, social support networks, mood and well-being in community-dwelling elderly. International Journal of Geriatric Psychiatry, 27(7), 694-700.

Granovetter, M. S. (1973). The strength of weak ties. American Journal of Sociology, 78(6), 1360-1380.

Hauge, S., \& Kirkevold, M. (2012). Variations in older persons' descriptions of the burden of loneliness. Scandinavian Journal of Caring Sciences, 26, 553-560.

Hawkley, L. C., \& Cacioppo, J. T. (2010). Loneliness matters: A theoretical and empirical review of consequences and mechanisms. Annals of Behavioral Medicine, 40(2), 218-227.

Heinrich, L. M., \& Gullone, E. (2006). The clinical significance of loneliness: A literature review. Clinical Psychology Review, 26(6), 695-718

Hersberger, J. A. (2003). A qualitative approach to examining information transfer via social networks among homeless populations. The New Review of Information Behaviour Research: Studies of Information Seeking in Context, 4, 95-108.

Hochschild, A. R. (1997). The second shift. Aron Books.

Holt-Lunstad, J., Smith, T. B., Baker, M., Harris, T., \& Stephenson, D. (2015). Loneliness and social isolation as risk factors for mortality: A meta-analytic review. Perspectives on Psychological Science, 10(2), 227-237.

Jiménez Ruiz, I., \& Moya, M. (2018). The family caregiver. A naturalised sense of obligation in women to be 
caregivers. Enfermería Global, 49, 434-447.

Juratovac, E., \& Zauszniewski, J. A. (2014). Full-time employed and a family caregiver: A profile of women's workload, effort, and health. Women's Health Issues, 24(2), 187-196. https://doi.org/ 10.1016/j.whi.2014.01.004

Karnick, P. M. (2005). Feeling lonely: Theoretical perspectives. Nursing Science Quarterly, 18(1), 7-12.

Kovacs, B., Caplan, N., Grob, S., \& King, M. (2021). Social networks and loneliness during the covid-19 pandemic. Socius: Sociological Research for a Dynamic World, 7. https://doi.org/10.1177\%2F2378 023120985254

Lindgren, B. M., Sundbaum, J., Eriksson, M., \& Graneheim, U. H. (2014). Looking at the world through a frosted window: Experiences of loneliness among persons with mental ill-health. Journal of Psychiatric and Mental Health Nursing, 21, 114-120.

Lubbers, M. J., Valenzuela-García, H., Escribano, P., Molina, J. L., Casellas, A., \& Grau Rebollo, J. (2020). Relationships stretched thin: Social support mobilization in poverty. Annals of the American Academy for Political and Social Science, 689(1), 65-88.

Marquand, D. (2004). Decline of the public: The hollowing out of citizenship. Polity Press.

Matias, T., Dominski, F. H., \& Marks, D. F. (2020). Human needs in covid-19 isolation. Health Psychology, 25(7), 871-882.

McCann, T. V., \& Lubman, D. I. (2017). Stigma experience of families supporting an adult member with substance misuse. International Journal of Mental Health Nursing, 27(2), 693-701.

McCarty, C., Lubbers, M. J., Vacca, R., \& Molina, J. L. (2019). Conducting personal network research: $A$ practical guide. Guilford Press.

McPherson, M., Smith-Lovin, L., \& Cook, J. M. (2001). Birds of a feather: Homophily in social networks. Annual Review of Sociology, 27, 415-444.

Molina, J. L., García-Macías, A., Lubbers, M. J., \& Valenzuela-García, H. (2019). The embeddedness of social capital in personal networks. Network Science, 8(2). https://doi.org/10.1017/nws.2019.30

Norvilitis, J. M., Scime, M., \& Lee, J. S. (2002). Courtesy stigma in mothers of children with attentiondeficit/hyperactivity disorder: A preliminary investigation. Journal of Attention Disorders, 6(2), 61-68.

Ortiz-Ospina, E., \& Roser, M. (2020). Loneliness and social connections. Our World in Data. https://our worldindata.org/social-connections-and-loneliness

Ozawa-de Silva, C., \& Parsons, M. (2020). Toward an anthropology of loneliness. Transcultural Psychiatry, 57(5), 613-622.

Pattison, E. N., Defrancisco, D., Wood, P., Frazier, H., \& Crowder, J. (1975). A psycho-social kinship model for family therapy. American Journal of Psychiatry, 132, 1246-1251.

Perlman, D., \& Peplau, L. A. (1981). Toward a social psychology of loneliness. In R. Gilmour \& S. Duck (Eds.),
Personal relationships: 3. Relationships in disorder (pp. 31-56). Academic Press.

Pinquart, M., \& Sörensen, S. (2001). Influences on loneliness in older adults: A meta-analysis enhanced reader. Basic and Applied Social Psychology, 23(4), 245-266.

Putman, R. (2001). Bowling alone: The collapse and revival of American community. Touchstone Books.

Refaeli, T., \& Achdut, N. (2020). Perceived poverty, perceived income adequacy and loneliness in Israeli young adults: Are social capital and neighbourhood capital resilience factors? Health and Social Care in Community. Advance online publication. https://onlinelibrary.wiley.com/doi/epdf/10.1111/ hsc. 13177

Russell, D. W., Cutrona, C. E., McRae, C., \& Gomez, M. (2012). Is loneliness the same as being alone? The Journal of Psychology, 146 (1/2), 7-22.

Savolainen, I., Oksanen, A., Kaakinen, M., Sirola, A., \& Paek, H. (2020). The role of perceived loneliness in youth addictive behaviors: Cross-national survey study. JMIR Mental Health, 7(1). https://doi.org/ 10.2196/14035

Schaefer, C., Coyne, J. C., \& Lazarus, R. S. (1981). The health-related functions of social support. Journal of Behavioral Medicine, 4, 381-406.

Silverstein, M., \& Giarrusso, R. (2010). Ageing and family life: A decade review. Journal of Marriage and Family, 72(5), 1039-1058.

Small, M. L. (2017). Someone to talk to. Oxford University Press.

Söderberg, P., \& Fry, D. P. (2017). Anthropological aspects of ostracism. In D. W. Kipling \& S. A. Nida (Eds.), Ostracism, exclusion, and rejection (pp. 258-272). Routledge.

Stanley, M., Moyle, W., Ballantyne, A., Jaworski, K., Corlis, M., Oxlade, D., Stoll, A., \& Young, B. (2010). Nowadays you don't even see your neighbours: loneliness in the everyday lives of older Australians. Health \& Social Care in the Community, 18, 407-414.

Stein, J. Y., \& Tuval-Mashiach, R. (2015a). The social construction of loneliness: An integrative conceptualisation. Journal of Constructivist Psychology, 28(3), 210-227. https://doi.org/10.1080/10720537. 2014.911129

Stein, J. Y., \& Tuval-Mashiach, R. (2015b). Loneliness and isolation in life-stories of Israeli veterans of combat and captivity. Psychological Trauma: Theory, Research, Practice, and Policy, 7(2), 122-130.

Stek, M. L., Vinkers, D. J., Gussekloo, J., Beekman, A. T. F., van der Mast, R. C., \& Westendorp, R. G. J. (2005). Is depression in old age fatal only when people feel lonely? American Journal of Psychiatry, 162(1), 178-180.

Thoits, P. A. (2010). Stress and health: Major findings and policy implications. Journal of Health and Social Behavior, 51, S41-S53.

Twenge, J. M., Spitzberg, B. H., \& Campbell, W. K. (2019). 
Less in-person social interaction with peers among U.S. adolescents in the 21st century and links to loneliness. Journal of Social and Personal Relationships, 36(6), 1892-1913.

Valenzuela-Garcia, H. (2020). Fuzzy Frontiers: Telework and work-life balance in COVID-19 Spain. Exertions. https://doi.org/10.21428/1d6be30e.962a9633

Valenzuela-Garcia, H., Lubbers, M. J., \& Molina, J. L. (2020). Vivo entre cuatro paredes. La vulnerabilidad relacional en contextos de exclusión social [I live within four walls. Relational vulnerability in contexts of social exclusión]. FOESSA.

Vasileiou, K., Barnett, J., Barreto, M., Vines, J., Atkinson, M., Lawson, S., \& Wilson, M. (2017). Experiences of loneliness associated with being an informal caregiver: A qualitative investigation. Frontiers in Psychology, 8. https://doi.org/10.3389/fpsyg.2017.00585

Victor, C. R., \& Yang, K. (2012). The prevalence of loneliness among adults: A case study of the United Kingdom. Journal of Psychology: Interdisciplinary and Applied, 146(1/2), 85-104. https://doi.org/10.1080/ 00223980.2011 .613875

Vidal, F., \& Halty, A. (2020). Parte segunda: La soledad del siglo XXI [Part two: Loneliness in the 21st century]. In A. J. Menéndez (Ed.), Informe España 2020 [Report Spain 2020]. Universidad Pontificia Comillas.
Waldinger, R. J., Cohen, S., Schulz, M. S., \& Crowell, J. A. (2015). Security of attachment to spouses in late life: Concurrent and prospective links with cognitive and emotional well-being. Clinical Psychological Science, 3(4), 516-529.

Weiss, R. S. (1973). Loneliness: The experience of emotional and social isolation. MIT Press.

Weiss, R. S. (1974). The provisions of social relationships. In Z. Rubin (Ed.), Doing unto others: Joining, molding, conforming, helping, loving (pp. 17-26). PrenticeHall.

Weiss, R. S. (1998). A taxonomy of relationships. Journal of Social and Personal Relationships, 15, 671-683.

Yang, K., \& Victor, C. (2011). Age and loneliness in 25 European nations. Ageing and Society, 31, 1-21.

Yu, Q., Mazzoni, S., Lauzon, M., Borgatti, A., Caceres, N., Miller, S., Dutton, G., \& Salvy, S. J. (2020). Associations between social network characteristics and loneliness during pregnancy in a sample of predominantly African American, largely publicly-insured women. Maternal and Child Health Journal, 24(12), 1429-1437.

Zhao, R., \& Cao, L. (2010). Social change and anomie: A cross-national study. Social Forces, 88(3), 1209-1229.

\section{About the Authors}

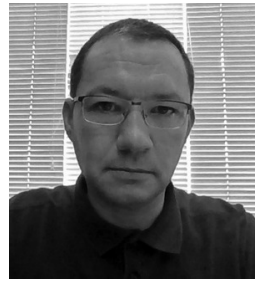

Hugo Valenzuela-Garcia is an associate professor at the Department of Social and Cultural Anthropology and a member of the Research Center in Entrepreneurship and Social Innovation (CREIS) of the $\mathrm{UAB}$, Spain. As an anthropologist, he has conducted fieldwork on fishermen in Malaysia, peasants in Mexico, and Asian entrepreneurship in Barcelona. His main fields of interest are poverty, precariousness and work, consumption, and other classical issues in cultural ecology and economic anthropology.

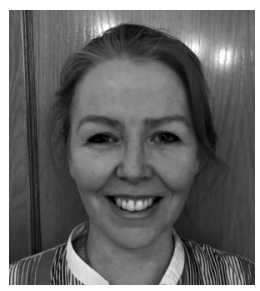

Miranda J. Lubbers is an associate professor in social and cultural anthropology at the Autonomous University of Barcelona, Spain, and the director of the Research Group of Fundamentally Oriented Anthropology (GRAFO). In 2021, she was granted a European Research Council Advanced Grant and the ICREA Acadèmia Award. Her research addresses social cohesion and social inclusion. In particular, she analyzes the role that formal and informal social relationships and settings have in the production, mitigation, or exacerbation of exclusion and segregation.

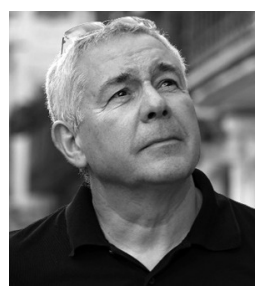

José Luis Molina is a full professor at the Department of Social and Cultural Anthropology (UAB). He is an economic anthropologist interested in livelihood practices in a globalised, digitalised, and unequal world. His approach is through mixed methods with an emphasis on ethnography and personal network analysis. Southeast Europe and Romania, in particular, are his main areas of interest. 